\title{
Synthesis of Temperature-Responsive Dextran-MA/PNIPAAm Particles for Controlled Drug Delivery Using Superhydrophobic Surfaces
}

\author{
Ana Catarina Lima $\cdot$ Wenlong Song $•$ Barbara Blanco-Fernandez $•$ Carmen Alvarez-Lorenzo • João F. Mano
}

Received: 19 October 2010 / Accepted: 19 January 2011 / Published online: 5 February 2011

(C) Springer Science+Business Media, LLC 2011

\begin{abstract}
Purpose To implement a bioinspired methodology using superhydrophobic surfaces suitable for producing smart hydrogel beads in which the bioactive substance is introduced in the particles during their formation.

Methods Several superhydrophobic surfaces, including polystyrene, aluminum and copper, were prepared. Polymeric solutions composed by photo-crosslinked dextranmethacrylated and thermal responsive poly $(N$-isopropylacrylamide) mixed with a protein (insulin or albumin) were dropped on the superhydrophobic surfaces, and the obtained millimetric spheres were hardened in a dry environment under UV light.

Results Spherical and non-sticky hydrogels particles were formed in few minutes on the superhydrophobic surfaces. The proteins included in the liquid formulation were homogeneously distributed in the particle network. The particles exhibited temperature-sensitive swelling, porosity and protein release rate, with the responsiveness tunable by the dextranMA/PNIPAAm weight ratio.
\end{abstract}

\footnotetext{
A. C. Lima $\cdot$ W. Song $\cdot$ J. F. Mano

3B's Research Group-Biomaterials, Biodegradables and Biomimetics Department of Polymer Engineering University of Minho AvePark, Zona Industrial da Gandra, S. Cláudio do Barco 4806-909 Caldas das Taipas, Guimarães, Portugal

A. C. Lima $\cdot$ W. Song $\cdot$ J. F. Mano $(\varangle)$

IBB - Institute for Biotechnology and Bioengineering

PT Government Associated Laboratory

Guimarães, Portugal

e-mail: jmano@dep.uminho.pt

B. Blanco-Fernandez $\cdot$ C. Alvarez-Lorenzo

Department of Farmacia y Tecnología Farmacéutica

Facultad de Farmacia Universidad de Santiago de Compostela

I 5782 Santiago de Compostela, Spain
}

Conclusions The proposed method permitted the preparation of smart hydrogel particles in one step with almost 100\% encapsulation yield. The temperature-sensitive release profiles suggest that the obtained spherical-shaped biomaterials are suitable as protein carriers. These stimuli-responsive beads could have potential to be used in pharmaceutical or other biomedical applications, including tissue engineering and regenerative medicine.

KEY WORDS biomimetics · delivery systems · dextranmethacrylate · encapsulation methods · inter-penetrated networks · PNIPAAm · smart systems · superhydrophobic surfaces

\section{INTRODUCTION}

Hydrogel systems with capability to deliver bioactive substances are useful in controlled drug delivery and tissue engineering (1-3). Micro- and millimeter-range polymeric particles are particularly suitable as drug carriers due to their high specific surface area, which avoids mass transfer limitations during the loading of bioactive substances and enables a fast response to environmental stimuli and, consequently, a fine regulation of the drug release rate (4-6).

Many encapsulation techniques have been proposed to produce polymeric particles containing bioactive substances either at the surface or embedded in the network $(7,8)$. Examples of such methodologies include solvent evaporation/extraction, cryogenic solvent extraction, phase separation (coacervation), polyelectrolyte complexation, interfacial polymerization, spray drying, spray chilling, spray desolvation and supercritical fluids technology. The processes are selected according to the nature of the polymers and the bioactive substances, the therapeutic 
application and the duration of the treatment. The chosen method determines particle shape, mean size and distribution, porosity, surface topography and drug entrapment efficiency. However, the need of using organic/toxic solvents or high temperature, the environmental concerns related to the solvents removal, and the low encapsulation efficiency due the diffusion of the bioactive molecules to the solvents (9) may limit the applicability of the previously enumerated encapsulation methods. Moreover, hydrogel particles are mostly produced in a liquid environment starting from a monomer solution or emulsion. Since the polymer is insoluble in the liquid environment, the droplets containing the monomers harden as hydrogel structures as the polymerization occurs. Therefore, bioactive substances intended to be entrapped in the particles are partially lost by diffusion to the liquid medium, and, consequently, complete encapsulation is never achieved. Such issues have forced the search for improvements of existing techniques or the development of alternative methodologies. Like water droplets on a lotus leaf or on other natural superhydrophobic surfaces (10), liquid droplets acquire spherical shape when deposited on superhydrophobic surfaces and can be hardened as hydrogel structures under mild conditions, without being in contact with another liquid medium (11). In principle, any superhydrophobic substrates could be suitable for this method.

The main objective of this work was to implement a novel methodology involving superhydrophobic substrates for obtaining under mild conditions beads that combine dextran-methacrylated (dextran-MA) and poly $(\mathcal{N}$-isopropylacrylamide) (PNIPAAm) for controlled release applications, and with high encapsulation efficiency. Low and high molecular weight proteins, namely insulin and bovine serum albumin (BSA), respectively, were chosen as models of bioactive substances. Different superhydrophobic surfaces were tested as substrates. Polystyrene, copper and aluminum plates were treated at the surface, applying various technologies, to attain hierarchical structures with protrusions and valleys and covered by a hydrophobic component, mimicking the features of superhydrophobic plant leaves (10). Polysaccharides are widely used to prepare hydrogels for biomedical applications due to their biocompatibility, nontoxicity and, in many cases, biodegradability (12-14). Dextran is one kind of polysaccharides with long branched chains of D-glucopyranose residues with 1,6- and some 1,3-glucosidic linkages $(4,15,16)$, which is obtained from bacterial cultures. Due to its good compatibility with human body, dextran has been used as blood plasma substitute and in drug delivery $(17,18)$. Dextran is commonly used as a component of colonspecific delivery systems because of its stability in stomach and small intestine. In the large intestine, it is degraded by dextranase produced by anaerobic Gram-negative intestinal bacteria (17). Besides its stability under mild acidic and basic conditions and biodegradable properties, dextran contains a large number of hydroxyl groups for conjugation that could extend their properties. On the other hand, PNIPAAm exhibits a low critical solution temperature (LCST) at around $32^{\circ} \mathrm{C}$ in aqueous medium and has been widely used in the preparation of smart hydrogels for a variety of biomedical applications (19). As discussed elsewhere, hydrophilic polysaccharides incorporated into PNIPAAm hydrogels may help to fasten the response to temperature, as compared with the pure PNIPAAm, and may prevent the so-called skin effect (20). Several interpenetrated (IPN) and semi-interpenetrated (semi-IPN) networks of PNIPAAm have been proposed as stimuliresponsive materials for drug delivery applications (2123). The semi-IPN Dextran-PNIPAAm hydrogel developed in this work was chosen to demonstrate the possibility of producing smart beads for drug delivery applications using superhydrophobic surfaces.

\section{MATERIALS AND METHODS}

\section{Materials}

Superhydrophobic surfaces were obtained using polystyrene (PS, granules of a grade for injection molding), and commercial plates of copper $(\mathrm{Cu})$ and aluminum $(\mathrm{Al})$ Tetrahydrofuran (THF, 99.9\%), Ammonium hydroxide $(33 \%)$ was from Riedel de-Haen (Germany). Hydrochloric acid (HCl, 37\%) was provided by Panreac (Spain). Hydrofluoric acid (HF), ammonium persulfate (APS, 98\%), $1 \mathrm{H}, 1 \mathrm{H}, 2 \mathrm{H}, 2 \mathrm{H}$ - perfluorodecyltriethoxysilane (PFDTS, 97\%), N,N-methylenebisacrylamide (MBIS, 98\%), bovine serum albumin $(\mathrm{BSA}, \sim 66 \mathrm{kDa}, 96 \%)$, insulin $(\sim 5.7 \mathrm{kDa})$, albumin-FITC, phosphate-buffered saline (PBS) and dextran from Leuconostoc mesenteroides (MW 100-200 kDa) were purchased from Sigma-Aldrich Co. (St. Louis MO, USA). N-isopropylacrylamide (NIPAAm, 99\%) was supplied from Acros (Portugal), and Irgacure 2959 from Ciba (Portugal). All chemicals were used as received.

\section{Methods}

Processing and Characterization of Superhydrophobic Surfaces

PS superhydrophobic surfaces were prepared using a phase separation method (24-26). A PS solution $(70 \mathrm{mg} / \mathrm{ml})$ in THF was prepared and then mixed with ethanol $(2: 1.3 \mathrm{v} / \mathrm{v})$. The mixture was dispensed onto smooth PS commercial substrate which was then immersed in ethanol for $1 \mathrm{~min}$ and dried with nitrogen flow. In order to increase the 
superhydrophobicity of obtained surfaces, the rough PS surfaces were modified with PFDTS $(1 \% \mathrm{v} / \mathrm{v}$ in ethanol) after argon plasma treatment for $20 \mathrm{~s}$ at $30 \mathrm{~W}$ (Plasma Prep5, Gala Instruments, Germany).

$\mathrm{Cu}$ superhydrophobic surfaces were prepared by a chemical-based deposition method (27). Briefly, Cu commercial substrates were immersed in ammonia (ammonium hydroxide) aqueous solution, $\mathrm{pH} 9-10$, at $4^{\circ} \mathrm{C}$. After 5 days the surfaces were collected, washed with water and completely dried in air. Finally, the $\mathrm{Cu}$ plates were immersed in a PFDTS solution $(1 \% \mathrm{v} / \mathrm{v}$ in ethanol) during at least $24 \mathrm{~h}$ and then dried in air.

$\mathrm{Al}$ superhydrophobic surfaces were prepared by chemical etching (28). An etchant solution was prepared by mixing $40 \mathrm{ml}$ of $37 \% \mathrm{HCl}, 12.5 \mathrm{ml}$ of water and $2.5 \mathrm{ml}$ of $\mathrm{HF}$ and dropped on $\mathrm{Al}$ substrates. After $15 \mathrm{~s}$, surfaces were washed with water in an ultrasonic bath and dried at $80^{\circ} \mathrm{C}$ in air. Finally, the $\mathrm{Al}$ plates were immersed in a PFDTS solution $(1 \% \mathrm{v} / \mathrm{v}$ in ethanol) during at least $24 \mathrm{~h}$ and then dried at air.

\section{Water Contact Angle and Surface Roughness}

The wettability of the surfaces was evaluated in Static Water Contact Angle (WCA) measurements by a OCA15+ goniometer (DataPhysics, Germany) and the sessile drop method. Distilled pure water $(5 \mu \mathrm{l})$ was dropped on the surfaces, and pictures were taken after stabilization of the water drop. The experiments were carried out in triplicate on different areas of the surfaces. Scanning Electron Microscopy (SEM, Leica Cambridge S-360, UK) was used to observe the roughness of the $\mathrm{PS}, \mathrm{Cu}$ and $\mathrm{Al}$ surfaces before and after being treated.

\section{Dextran Modification and Characterization}

Dextran was modified as previously described (29). Briefly, dextran (25 g) was dissolved in DMSO (225 ml) under nitrogen atmosphere to prevent the oxidation of the dextran by the oxygen. After dissolution of 4-(N,Ndimethylamino)pyridine $(5 \mathrm{~g})$, glycidyl methacrylate (20.5 ml) was added. The solution was stirred at room temperature for $48 \mathrm{~h}$, and then the reaction was stopped by adding an equimolar amount of concentrated $\mathrm{HCl}$ solution to neutralize 4-(N,N-dimethylamino)pyridine. The reaction mixture was transferred to a dialysis tube (MWCO 12,400 Da) and dialyzed during 1 month against demineralised water. Finally, dextran-MA was lyophilized (Manifold freeze-drier, Telstar cryodos, Spain). The degree of methacrylation was determined by ${ }^{1}$ H-NMR analysis of dextran and modified dextran $(0.3 \mathrm{~g})$ in deutered water $(0.7 \mathrm{ml})$, in a NMR Mercury $300(300 \mathrm{MHz}$, Varian, Australia). The spectra were analyzed using the MestreNova software (MestreLab, Spain). The degree of methacrylation (MD) was estimated by comparing the sum of the integral of the signals obtained at 5.75 and $6.2 \mathrm{ppm}$ with the sum of the integrals of signals that appear at 4.95 and 5.1 ppm (Fig. 1).

\section{Preparation and Characterization of the Hydrogel Beads}

Solutions of Dextran-MA (without PNIPAAm) were prepared in deionized water with Irgacure 2959. Irgacure was
Fig. I 'H NMR spectra of dextran before and after reaction with GMA to obtain the methacrylated derivative. The peaks used to calculate the degree of methacrylation are indicated with arrows.

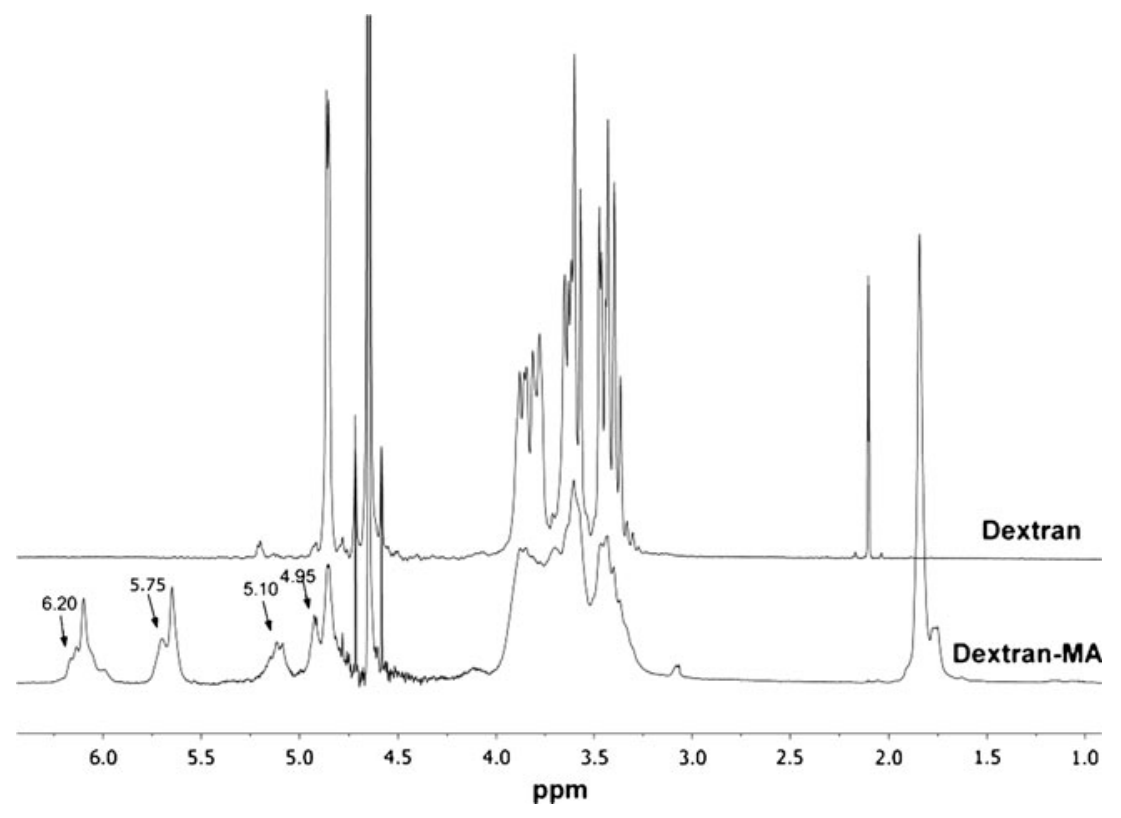


first dissolved in deoinized water $(0.2 \% \mathrm{w} / \mathrm{v})$, and then dextran-MA was added up to reach two different concentrations: $5 \% \mathrm{w} / \mathrm{v}$ and $15 \% \mathrm{w} / \mathrm{v}$.

PNIPAAm was synthesized as follows. NIPAAm $(10 \%$ $\mathrm{w} / \mathrm{v})$, a redox initiator, APS $(8 \% \mathrm{w} / \mathrm{w}-\mathrm{NIPAAm})$, and a crosslinking agent MBIS (3\% w/w-NIPAAm) were dissolved in deionized water at room temperature. We tried also to use TEMED as the redox pair, but the polymerization occurred too fast, and it was impossible to drop the solution on superhydrophobic surfaces before the reaction was completed. Thus, ammonium persulfate itself was enough to induce the polymerization.

Irgacure $(0.2 \% \mathrm{w} / \mathrm{v})$ and BSA or insulin $(5 \mathrm{mg} / \mathrm{ml})$ were added to the PNIPAAm solution. Finally, different quantities of dextran-MA were dissolved in the solution to prepare the formulations summarized in Table I. Controls were prepared using the same amounts of polymers but without BSA and Insulin.

The above-described solutions were dropped $(5 \mu \mathrm{l})$ on the superhydrophobic surfaces and put under UV light at $254 \mathrm{~nm}$ (U.V. Lamp system Triwood, 6×36W, Helios Italquartz s.r.l. MILANO-ITALY). Different irradiation times were tested, and $10 \mathrm{~min}$ was chosen as an adequate irradiation time. Under these conditions, solid hydrogel beads were obtained and could be easily detached from the superhydrophobic surface where no apparent residue was found.

\section{Fourier Transform Infrared Spectroscopy}

FTIR spectra of freeze-dried PNIPAAM, dextran-MA before photocrosslinking, dextran-MA after crosslinking and dextran-MA/PNIPAAm hydrogels were recorded in a IR-Prestige-21 (FTIR Shimadzu, Japan) using the $\mathrm{KBr}$ pellet technique.

\section{Water Uptake}

Beads (5 spheres) were dried for $24 \mathrm{~h}$ at air and then weighted and immersed in $10 \mathrm{ml}$ of PBS, pH 7.4, at $37^{\circ} \mathrm{C}$ and $4^{\circ} \mathrm{C}$ (24 h cycles). At pre-established periods of time, the beads were collected after removing the excess of PBS solution with filter paper and immediately weighed. The swelling degree was estimated as follows:

$\%$ Water uptake $=\frac{\left(m_{i}-m_{0}\right)}{m_{0}} \times 100$

In this equation, $m_{i}$ is the swollen beads weight and $m_{0}$ is the weight of dried beads.

\section{Surface Morphology}

The surface morphology of the beads was visualized by stereomicroscopy (Zeiss-Stemi 1000 PG-HITEC, Germany) and SEM (Leica Cambridge S-360, UK). For SEM analysis, the spheres were immersed in PBS at $4^{\circ} \mathrm{C}$ or $37^{\circ} \mathrm{C}$ during $24 \mathrm{~h}$, then removed from the medium and immediately frozen at $-80^{\circ} \mathrm{C}$. Finally, the spheres were freeze-dried and visualized after gold coating.

\section{In Vitro Protein Release}

Ten spheres of each formulation were placed in $8 \mathrm{ml}$ of PBS, $\mathrm{pH}$ 7.4. The vials containing the spheres were kept under agitation (at approximately $60 \mathrm{rpm}$ ) at room temperature or in a water bath at $37^{\circ} \mathrm{C}$. At pre-established periods of time, aliquots of $500 \mu \mathrm{l}$ of the supernatant were taken out and replaced with equal volume of fresh PBS to maintain the volume constant during the release study. The amounts of insulin and BSA released were quantified using the Micro BCA $^{\text {тм }}$ Protein Assay Kit (Pierce, USA).

\section{Bioactive Substance Distribution}

In order to verify the distribution of a bioactive substance inside the beads, albumin labeled with fluorescent isothiocyanate (FITC) was encapsulated in the hydrogels as previously described for BSA. The beads were examined using a fluorescence microscope (Zeiss, Germany).
Table I Reagents Used to Prepare Dextran-MA/PNIPAAm Beads

\begin{tabular}{|c|c|c|c|c|c|c|c|c|}
\hline $\begin{array}{l}\text { Proportion } \\
\text { (Dextran-MA/PNIPAAm) }\end{array}$ & $\begin{array}{l}\text { Deionizer } \\
\text { water }\end{array}$ & $\begin{array}{l}\text { Dextran } \\
\text { MA }\end{array}$ & NIPAAm & APS & MBIS & BSA & Insulin & $\begin{array}{l}\text { Irgacure } \\
2959\end{array}$ \\
\hline $\begin{array}{l}1: 1 \\
1: 1\end{array}$ & \multirow{3}{*}{$\mathrm{l} \mathrm{ml}$} & 100 mg & \multirow{3}{*}{100 mg } & \multirow{3}{*}{$8 \mathrm{mg}$} & \multirow{3}{*}{$3 \mathrm{mg}$} & $\begin{array}{l}5 \mathrm{mg} \\
-\end{array}$ & $-\overline{5} \mathrm{mg}$ & \multirow{3}{*}{$2 \mathrm{mg}$} \\
\hline $\begin{array}{l}1: 5 \\
1: 5\end{array}$ & & 20 mg & & & & $\begin{array}{l}5 \mathrm{mg} \\
-\end{array}$ & $\begin{array}{l}- \\
5 \mathrm{mg}\end{array}$ & \\
\hline $\begin{array}{l}1: 10 \\
1: 10\end{array}$ & & 10 mg & & & & $\begin{array}{l}5 \mathrm{mg} \\
-\end{array}$ & $\begin{array}{l}- \\
5 \mathrm{mg}\end{array}$ & \\
\hline
\end{tabular}




\section{RESULTS AND DISCUSSION}

\section{Beads Development}

The main aim of this work was to produce hydrogel beads from droplets of dextran-MA and PNIPAAm dispersions deposited on superhydrophobic surfaces. Dextran was modified, adding methacrylate groups (Fig. 1) in order to turn it photocrosslinkable. Although various methods have been reported in literature to functionalize polysaccharides with polymerizable groups $(29,30)$, we chose a relatively simple and environmentally friendly approach that uses dimethyl sulfoxide (DMSO) as a polar aprotic solvent and a base as catalyst for the coupling reaction of GMA and dextran $(29,30)$. Functionalization of dextran is expected to occur mainly by way of transesterification, but the epoxide ring-opening mechanism cannot be discarded (30). Thus, dextran-MA is expected to consist of two region isomers, the 3-methacryloyl-1-glyceryl ether of dextran and the 2-methacryloyl-1-glyceryl ether of dextran (29). Several irradiation times were tried for the gelation of dextran-MA and dextran-MA/PNIPAAm beads under UV light irradiation; we concluded that crosslinking of the particles could be achieved after $10 \mathrm{~min}$. After this period, the particles presented an elastic behavior and a non-sticking touch. In the presence of the photoinitiator and UV light, the reactive unsaturated functional groups (vinyl groups) in dextran-MA backbone chains establish links between dextran-MA monomers. The preparation process is described in Fig. 2. The obtained beads were spherical and had about $1-1.5 \mathrm{~mm}$ of diameter.

\section{Superhydrophobic Surfaces}

Three different superhydrophobic surfaces based on polystyrene (PS), copper $(\mathrm{Cu})$ and aluminum $(\mathrm{Al})$ were prepared in this work for demonstrating the possibility that most kinds of superhydrophobic surfaces can be used to produce the hydrogel beads in this bioinspired methodology. These three surfaces exhibit rough topography, composed of hierarchical organized micro- and nano-scale structures (Fig. 3) that mimic those of superhydrophobic materials in Nature (10).

In the case of PS surfaces, the mixture of a solvent and a non-solvent of PS leads to both poor and rich PS phases (24). In the poor phase, polymer nuclei are formed by precipitation, and the rich phase aggregates around these nuclei in order to decrease the surface tension (24,31,32). SEM images (Fig. $3 \mathrm{Al}$ and A2) enabled visualization of the submicrometer spheres deposited during the precipitation within PS rich phase that agglomerated in larger micrometer structures. In order to increase the hydrophobicity of the PS surfaces, a chemical treatment was carried out. The plasma treatment activates the surface-generating hydroxyl groups on the PS surface. Hydroxyl groups are water-adsorbing sites, and then the fluorinated hydrocarbons present in PFDTS solution react with these groups, eliminating possible anchor points for the water molecules (33).

Copper surfaces were prepared by a chemical-based deposition method (27). After $\mathrm{Cu}$ substrate immersion in ammonia solution during 5 days, an uniform blue film of $\mathrm{Cu}(\mathrm{OH})_{2}$ was obtained. The micro and nano objects giving rise to the hierarchical roughness were obtained due to the

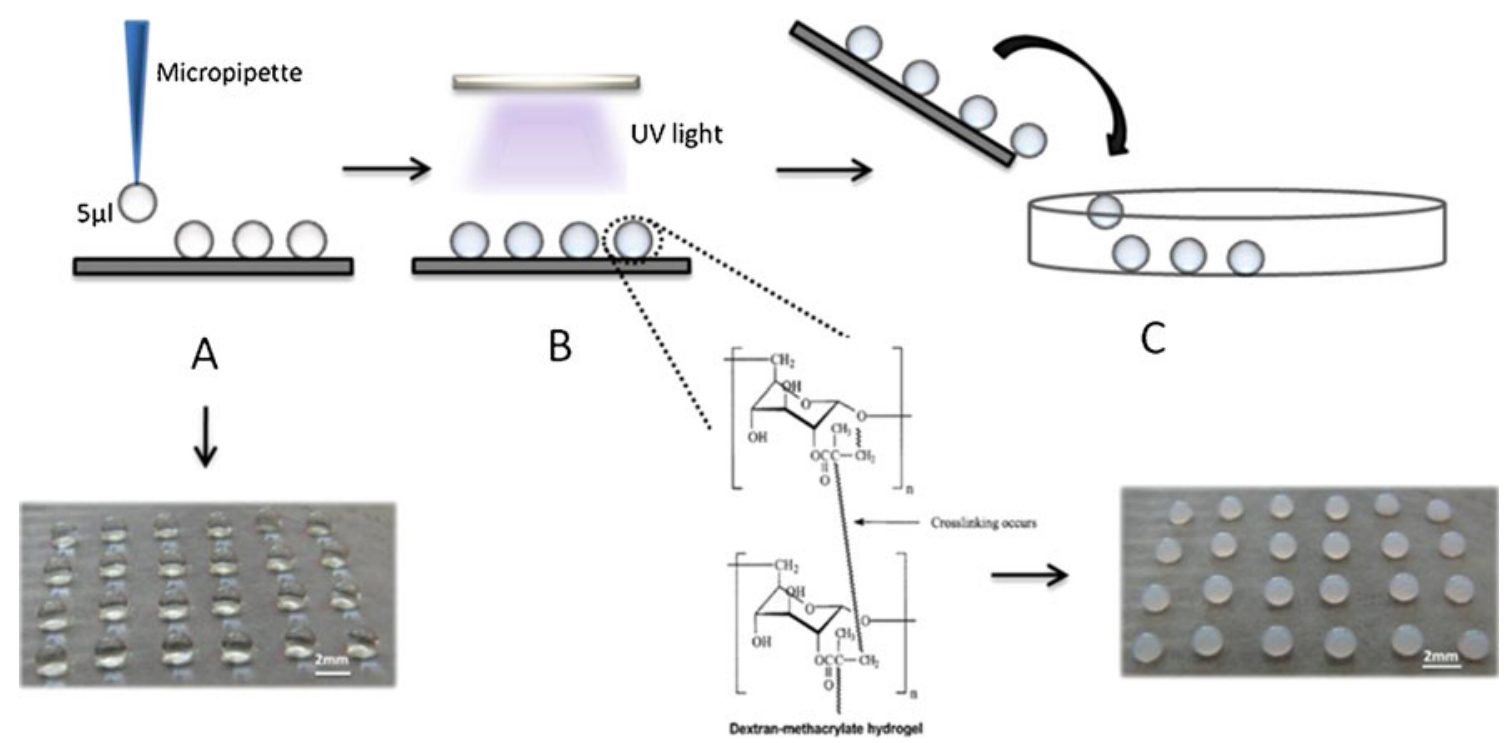

Fig. 2 Preparation of dextran-MA/PNIPAAm hydrogel beads using superhydrophobic surfaces: $(\mathbf{A})$ dropping of the polymer + drug solution on superhydrophobic surface; (B) beads photocrosslinking (UV light); (C) beads harvesting. 
formation of a compact structure similar to needles (nanoribbons) on the $\mathrm{Cu}$ surface (Fig. $3 \mathrm{~B} 1$ and $\mathrm{B} 2$ ).

Aluminum superhydrophobic surfaces were obtained by chemical etching and posterior surface fluorination (28). SEM images (Fig. $3 \mathrm{C} 1$ and C2) show the structure of $\mathrm{Al}$ superhydrophobic surfaces, evidencing the existence of both micro and nano roughness. PFDTS was used for increasing the hydrophobicity of these surfaces.

As shown on the top right side of SEM images, these three modified rough surfaces showed WCA values of $165^{\circ} \pm 4.9^{\circ}$, $164.4^{\circ} \pm 5.8^{\circ}$ and $163^{\circ} \pm 1.8^{\circ}$ for $\mathrm{PS}, \mathrm{Cu}$ and $\mathrm{Al}$, respectively, which were much higher than those of the initial smooth surfaces: $76.9^{\circ} \pm 1.4^{\circ}, 55.7^{\circ} \pm 3.0^{\circ}$ and $117^{\circ} \pm 1.9^{\circ}$, respectively. This means that the composition and hierarchical roughness of the treated surfaces greatly contributed to the superhydrophobicity.

In order to know the influence of the UV light used in this work on the superhydrophobic behavior, WCA was measured again after UV irradiation under the conditions used for the crosslinking reaction of Dextran-MA for $10 \mathrm{~min}$ and $20 \mathrm{~min}$. Only WCA values of PS superhydrophobic surfaces decreased after 20 min exposition and reached values below $150^{\circ}$. No changes were observed on the metallic substrates after 10 or 20 min of UV irradiation, which means that the surfaces maintain the superhydrophobic characteristics and can be used repeatedly in the processing of the particles.

\section{Beads Characterization}

FTIR analysis was used to qualitatively characterize the chemical composition of the materials. The FTIR spectra of PNIPAAm, dextran-MA before and after crosslinking and dextran-MA/PNIPAAm are shown in Fig. 4. Each spectrum shows a broad band in the range of 3700$3100 \mathrm{~cm}^{-1}$ corresponding to $\mathrm{O}-\mathrm{H}$ from dextran and $\mathrm{N}-\mathrm{H}$ from PNIPAAm stretching vibration. Also, hydroxyl groups of dextran are identified by a peak at about $1020 \mathrm{~cm}^{-1}$ (line $\mathrm{D})$, and the incorporation of methacrylate groups is proved by the presence of an ester band at $1715 \mathrm{~cm}^{-1}$ (line A). The peaks at $1650 \mathrm{~cm}^{-1}$ (line B) present in all spectra corresponds to $\mathrm{C}=\mathrm{C}$ in vinyl groups of dextran-MA and also to the amide groups characteristic of PNIPAAm. The $\mathrm{N}-\mathrm{H}$ characteristic group of PNIPAAm is observed in a
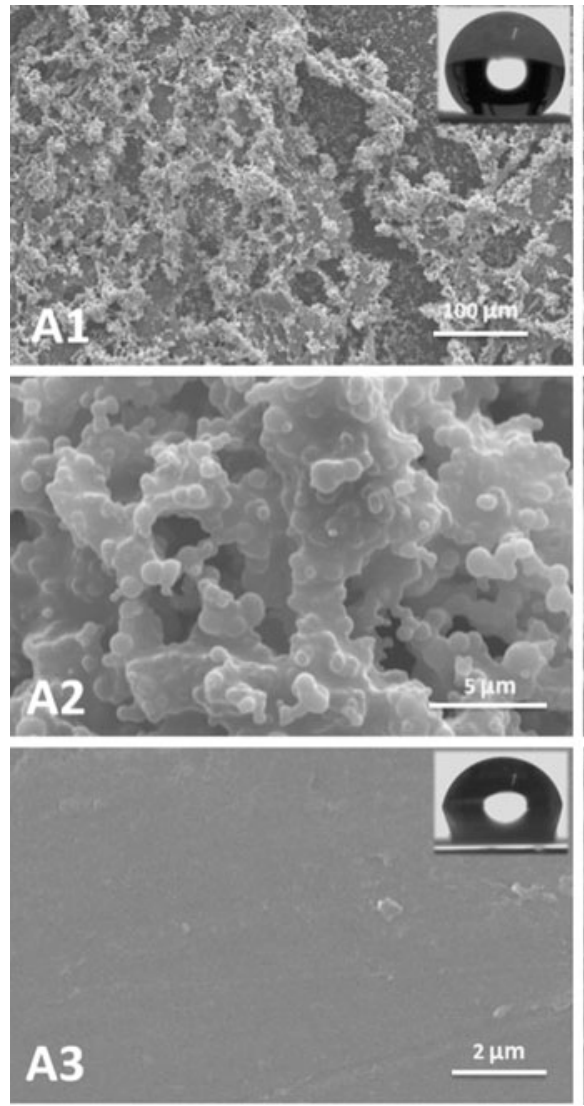
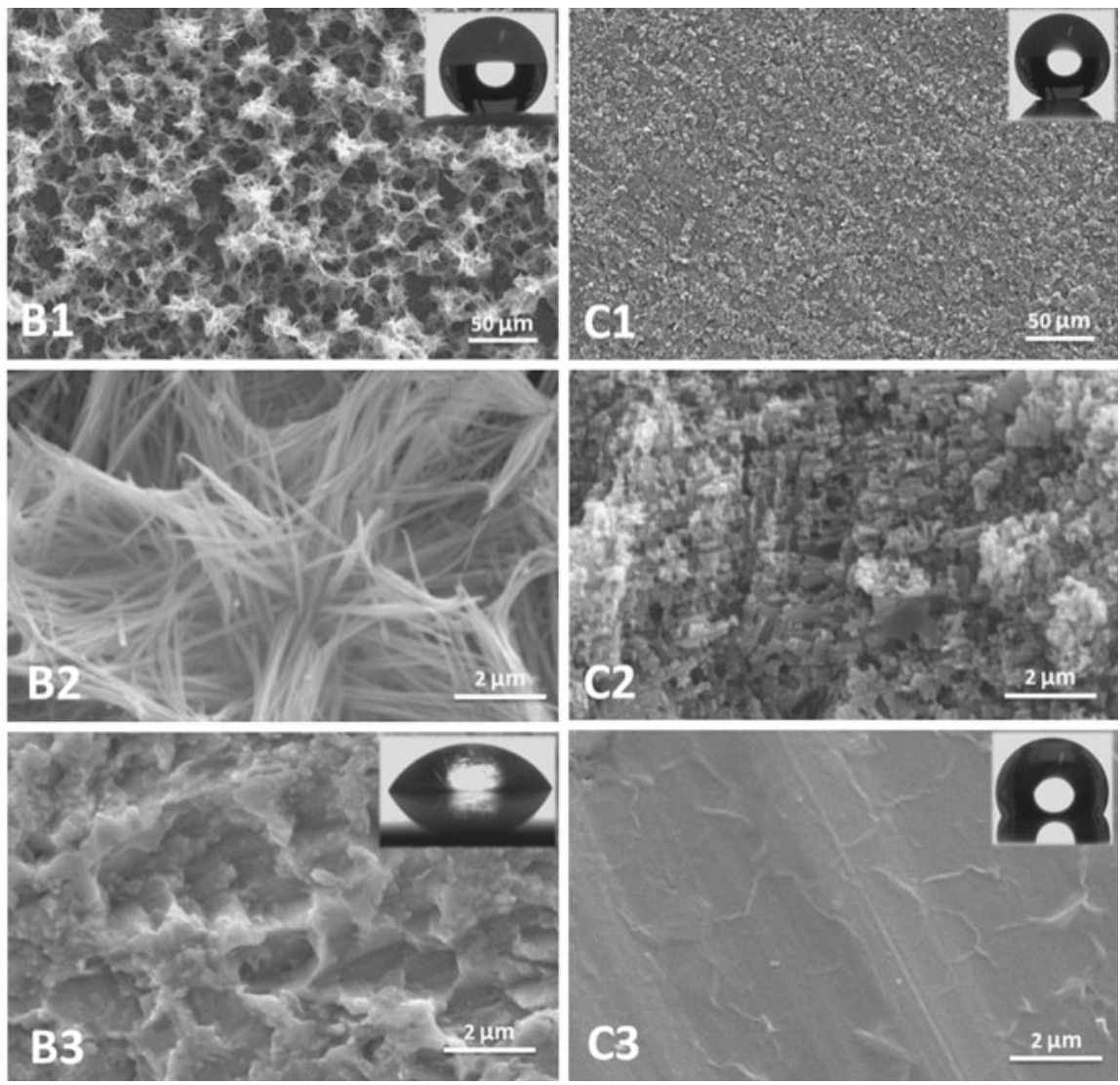

Fig. 3 SEM images: Al and A2: PS superhydrophobic surfaces using different magnifications; A3: smooth PS surface; BI and B2: Cu superhydrophobic surfaces using different magnifications; B3: untreated Cu substrate. CI and C2: Al superhydrophobic surfaces using different magnifications; $\mathbf{C 3}$ : smooth Al surface. The inset images show representative profiles of water drops deposited onto the surfaces. 
Fig. 4 FTIR spectra of PNIPAAm, dextran-MA before and after photocrosslinking and dextranMA/PNIPAAM hydrogels.

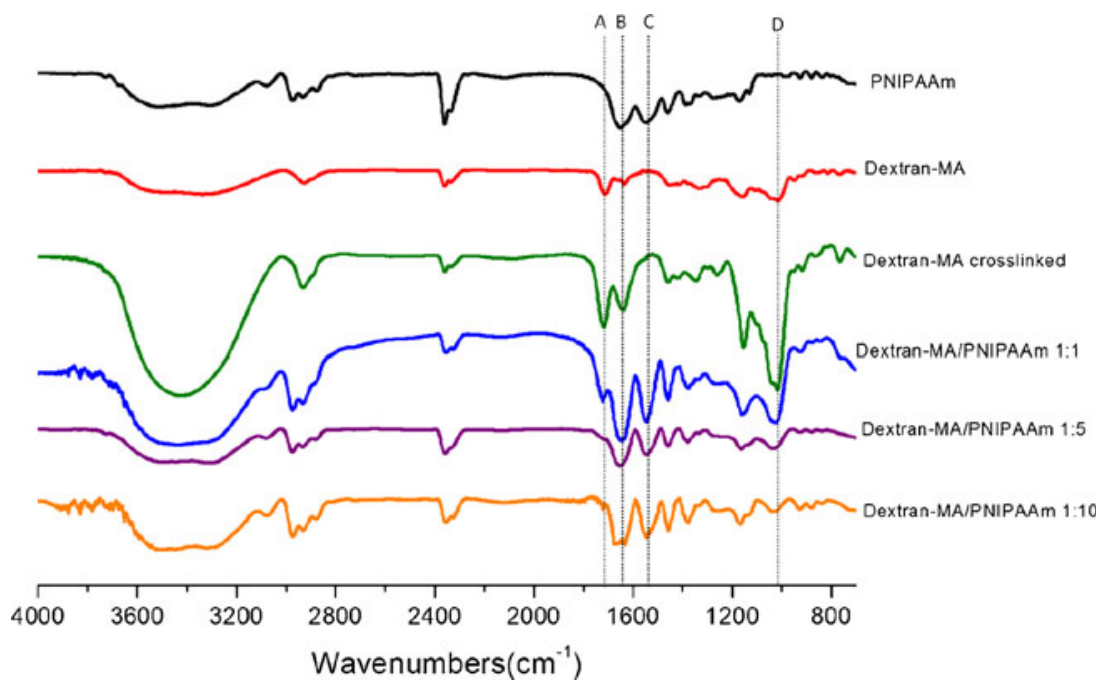

peak at about $1550 \mathrm{~cm}^{-1}$ (line $\mathrm{C}$ ), appearing only in PNIPAAm and in dextran-MA/PNIPAAm gels spectra, which proves the existence of both polymers in the beads.

\section{Water Uptake}

The purpose of combining PNIPAAm and dextran was to obtain temperature-responsive beads (20,21,34-36). The temperature sensitiveness of the beads was analyzed through the water uptake quantification once immersed in PBS solution for $24 \mathrm{~h}$ cycles at $4^{\circ} \mathrm{C}$ and $37^{\circ} \mathrm{C}$. The swelling ability of hydrogels is an important parameter in regulating many of their properties, namely permeability for hydrophilic or hydrophobic drugs, since the penetration of water molecules into the structure of the dry hydrogel promotes the relaxation of the chains and increases the pores size

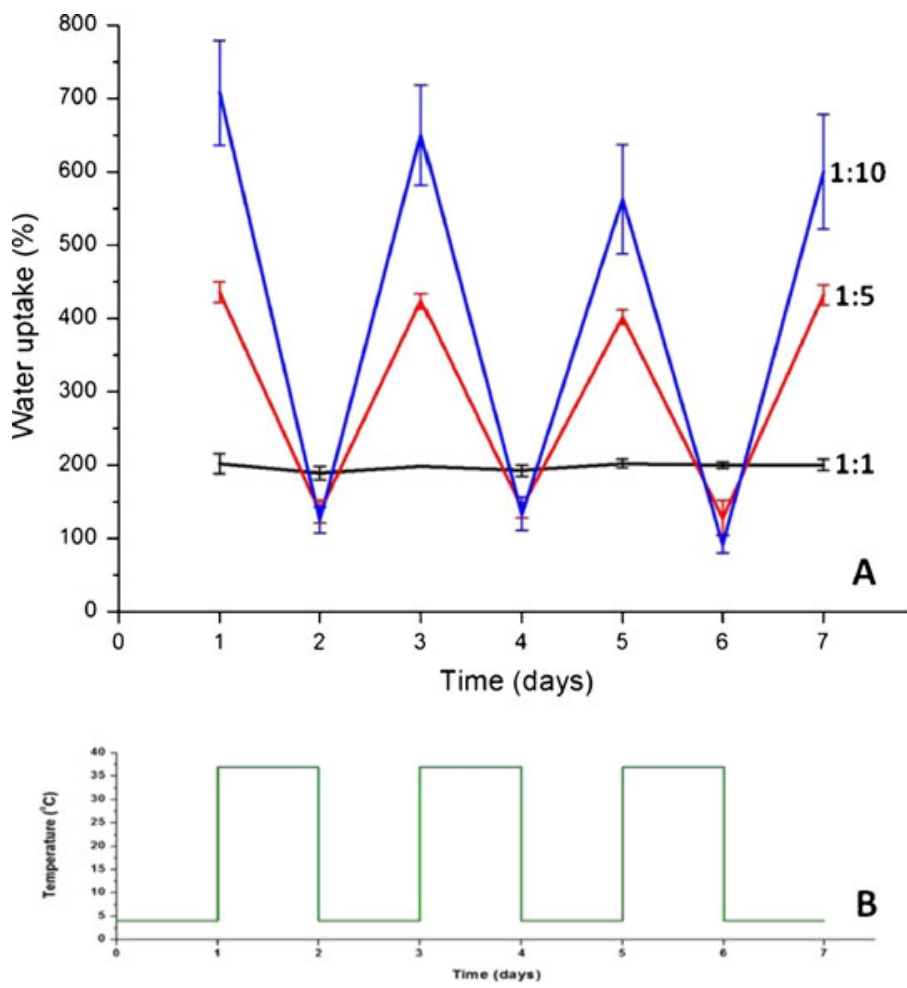

$4^{\circ} \mathrm{C}$
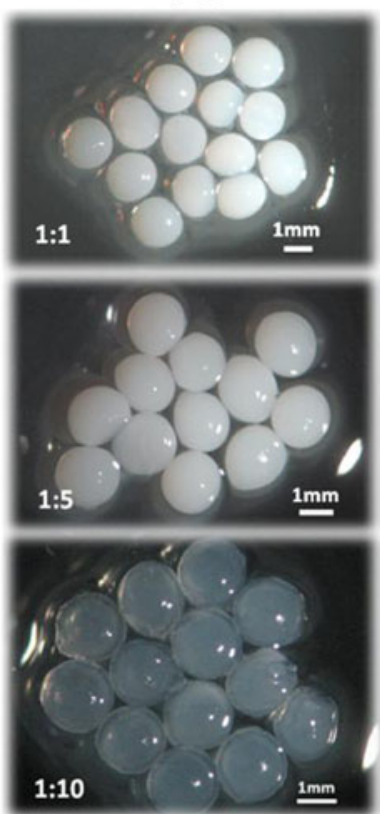

$B$
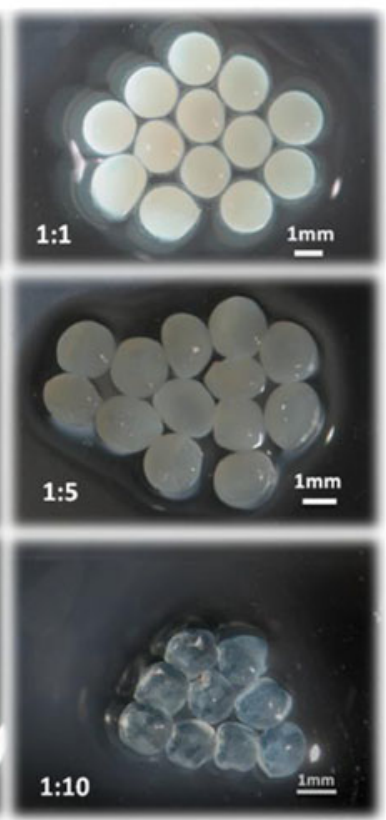

C

Fig. 5 (A) Water uptake of the beads prepared with different Dextran-MA/PNIPAAm proportions. Dried beads were immersed in PBS solution at pH 7.4 , and consecutive temperature switches were performed after periods of $24 \mathrm{~h}(\mathbf{B})$. (C) Dextran-MA/PNIPAAM beads at $4^{\circ} \mathrm{C}$ and $37^{\circ} \mathrm{C}$. Error bars represent the standard deviation. 
(37), modifying enzymatic or hydrolytic degradation, biocompatibility and mechanical characteristics (38).

The water uptake of $5 \%(\mathrm{w} / \mathrm{v})$ and $15 \%(\mathrm{w} / \mathrm{v})$ DextranMA hydrogels occurred in the first hour of testing, reaching an equilibrium value of about $470 \%$ for $5 \%(\mathrm{w} / \mathrm{v}$ ) DextranMA beads, and $270 \%$ for $15 \%(\mathrm{w} / \mathrm{v})$ Dextran-MA beads. Thus, the swelling ratio at $37^{\circ} \mathrm{C}$ increased when the concentration of the polymer decreased.

The incorporation of a non-thermo-sensitive polymer such as Dextran-MA in a thermo-responsive matrix such as PNIPAAm may lead to a certain attenuation of the sensitivity if the relative proportion of the non-thermosensitive polymer is high (39). In fact, the volume phase transition of the beads was brusquer as the content in PNIPAAm increased (Fig. 5A and C). Similar results have been observed on another IPN systems (40). The water uptake by hydrogels depends on the hydrophilic/hydrophobic characteristics of the material and the crosslinking degree. As reported (39), when a hydrophilic moiety as dextran-MA is present in a semi-IPN or IPN, the water uptake of the network increases. However, methacrylate groups grafted to dextran backbone are responsible for the hydrogel crosslinking, which means that an increase of dextran-MA content in the formulation raises the crosslinking density, resulting in a smaller swelling. These results are consistent with the water uptake results obtained for dextran-MA solely hydrogels. In the case of dextran-MA/PNIPAAM beads, an increase in dextran-MA/PNIPAAm weight ratio from 1:10 to $1: 1$ resulted in beads that swell less at $4^{\circ} \mathrm{C}$ (Fig. 5A) and shrink less at $37^{\circ} \mathrm{C}$, i.e., the higher the dextran-MA content, the smaller the temperature sensitiveness. At $4^{\circ} \mathrm{C}$ both polymers behave as hydrophilic and are able to absorb water, the degree of swelling being limited by the crosslinking density. Temperature sensitivity of PNIPAAM comes from the competition between the intraand intermolecular hydrogen bonding below and above LCST. When the temperature was increased to $37^{\circ} \mathrm{C}$, all the hydrogel beads containing PNIPAAm decreased their volume. The water uptake of dextran-MA/PNIPAm 1:5

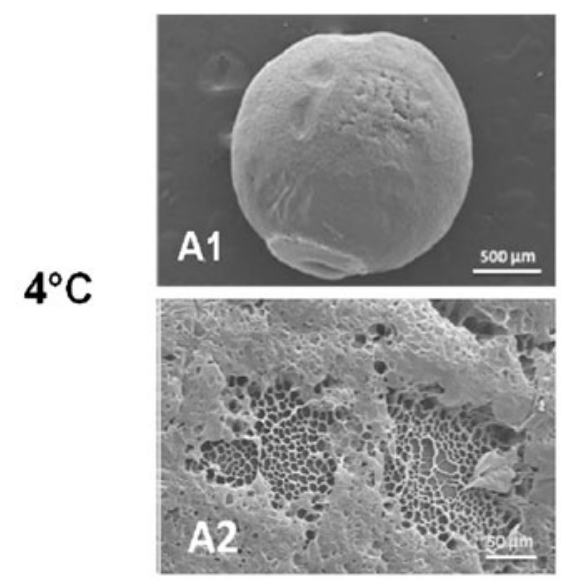

$1: 1$

$37^{\circ} \mathrm{C}$
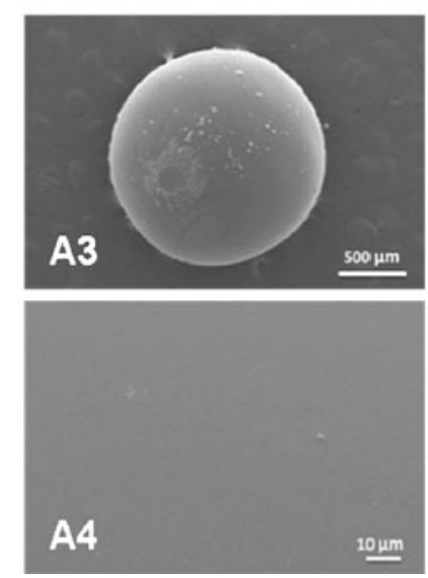
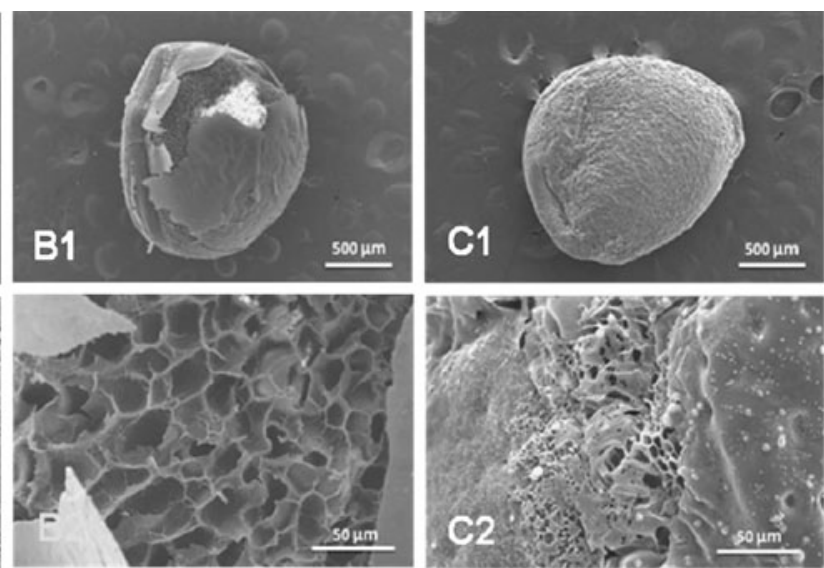

$1: 5$
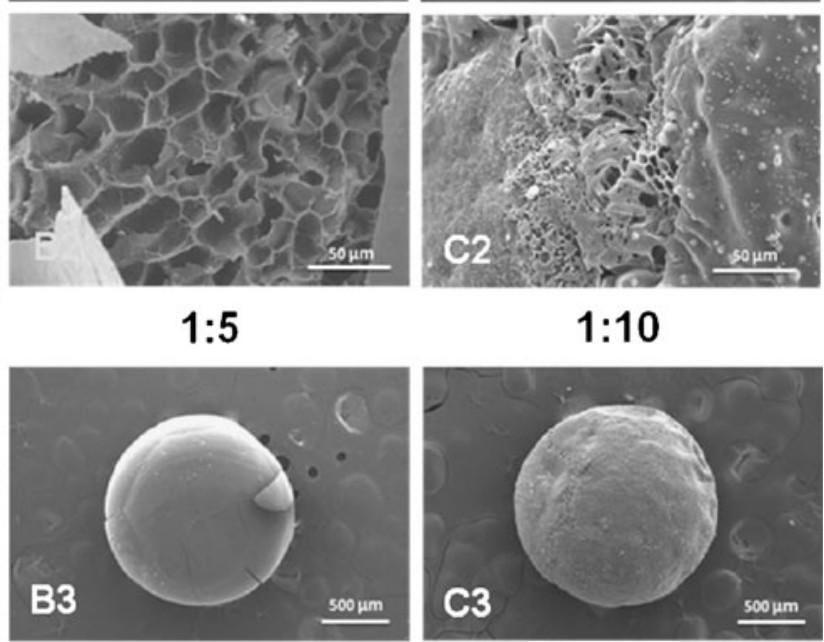

$1: 10$
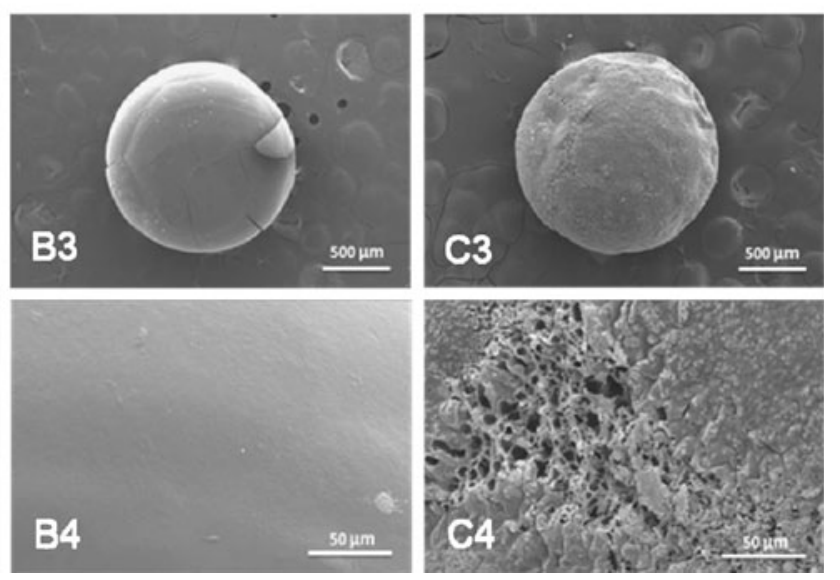

Fig. 6 SEM images of Dextran-MA/PNIPAAm freeze-dried beads; I:I proportion: $(\mathbf{A I})$ bead and $(\mathbf{A 2})$ respective surface at $4^{\circ} \mathrm{C} ;(\mathbf{A} 3)$ bead and $(\mathbf{A 4})$ respective surface at $37^{\circ} \mathrm{C} ; 1: 5$ proportion: $(\mathbf{B I})$ bead and $(\mathbf{B 2})$ respective surface at $4^{\circ} \mathrm{C} ;(\mathbf{B} 3)$ bead and $(\mathbf{B 4})$ respective surface at $37^{\circ} \mathrm{C} ; 1: 10$ proportion: $(\mathbf{C I})$ bead and $(\mathbf{C 2})$ respective surface at $4^{\circ} \mathrm{C} ;(\mathbf{C} 3)$ bead and $(\mathbf{C 4})$ respective surface at $37^{\circ} \mathrm{C}$. 
and 1:10 hydrogel beads decreased from $300 \%$ and $600 \%$ at $4^{\circ} \mathrm{C}$, up to $141 \%$ and $132 \%$, respectively, at $37^{\circ} \mathrm{C}$. The 1:1 proportion beads only showed tiny changes between the degree of swelling at $4^{\circ} \mathrm{C}(\sim 200 \%)$ and at $37^{\circ} \mathrm{C}$ $(192 \%)$, which indicates that the size of the PNIPAAm domains is not large enough (relative to those of dextran) to induce the swelling or shrinking of the structure in response to temperature changes.

The low hydration levels observed at higher temperatures and the cyclic behavior in the water uptake data seem to indicate that the deswelling of the beads is effective and that the so-called skin effect often observed in PNIPAAm hydrogels could be prevented by the addition of dextran (20).

\section{Morphological Analysis}

The morphology of the beads is an important feature for their pharmaceutical applications and for a better understanding of the release profiles of bioactive substances. After freeze drying, beads were analyzed by SEM, assuming that the main features of the particle structure in equilibrium are kept during the processing. It has been shown that this technique removes the solvent with minimal disturbance of dextran hydrogels structures (41).

The outer surface and transversal cuts of the dextranMA photocrosslinked hydrogels evidenced an almost perfect spherical shape with porous structure that resembles those previously reported for dextran-based hydrogels prepared using other methods $(18,41)$. Transversal cut micrographs showed heterogeneous porosity, which evidences different levels of crosslinking caused by the attenuation of UV irradiation in the inner regions of the beads. In fact, UV penetration is significantly reduced by the distance $(18,41)$, resulting in smaller pores at the surface and larger pores in the interior of the bead. The surface morphology also varied with dextran concentration, the surface of dextran-MA $15 \%$ beads being smoother than that of the $5 \%$ ones. The increase in dextran-MA concentration makes the polymer density in the particle increase and the hydrogel structure become more compact, which is in agreement with the water uptake results.

SEM images of freeze-dried dextran-MA/PNIPAAM beads after being immersed in a PBS solution during $24 \mathrm{~h}$ at $4^{\circ} \mathrm{C}$ also showed surface porous structure (Fig. 6). This may be explained by the swelling ability and inherent increase of pore size of the hydrogels when immersed in a medium at temperature below LCST of PNIPAAm (37). The surface of the beads that were immersed at $37^{\circ} \mathrm{C}$ showed a smoother morphology without pores, which could be explained by the shrinking of the network at this temperature. SEM images also showed that the diameter of the beads was bigger when immersed at $4^{\circ} \mathrm{C}$ than at $37^{\circ} \mathrm{C}$. These results are consistent
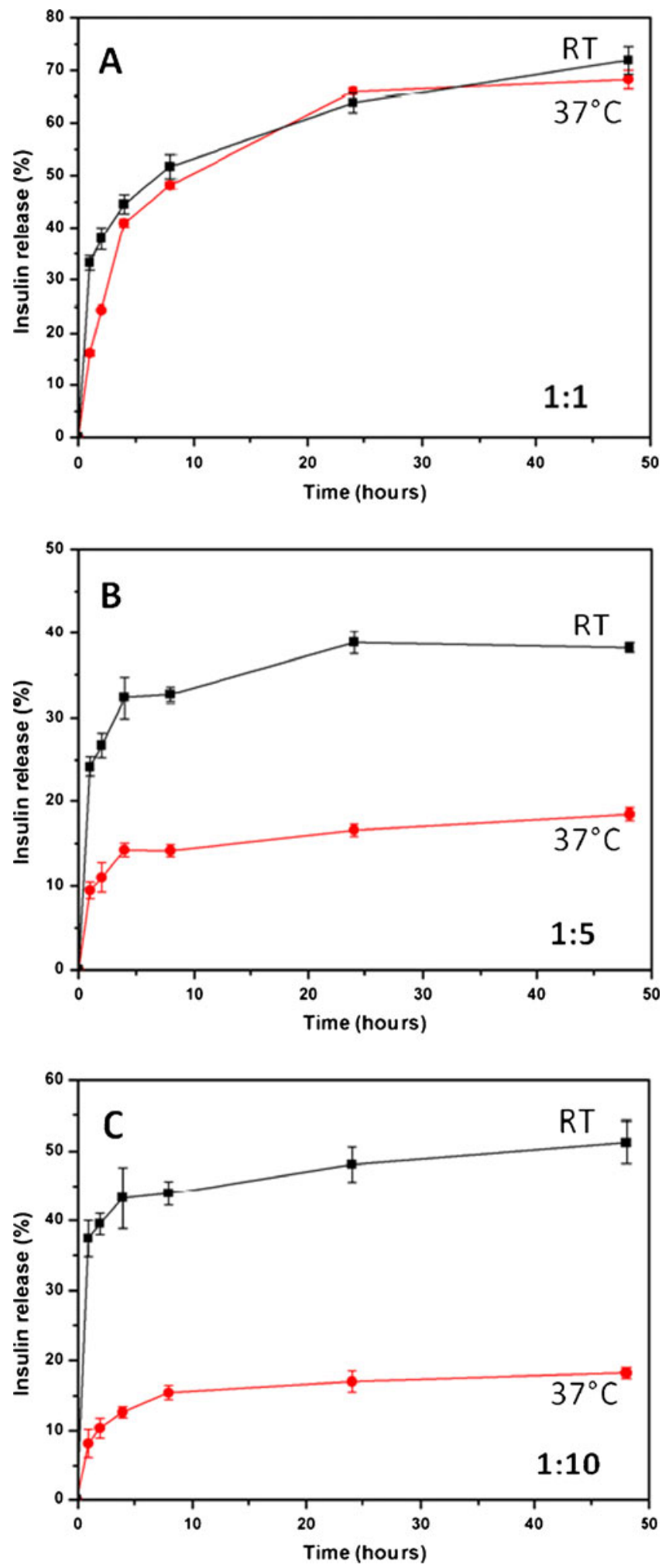

Fig. 7 Insulin cumulative release from Dextran-MA/PNIPAAm beads at room temperature and at $37^{\circ} \mathrm{C}:(\mathbf{A}) 1: 1 ;(\mathbf{B}) 1: 5$ and $(\mathbf{C}) 1: 10$ proportion. Error bars represent the standard deviation. 
with water uptake data shown in Fig. 5A and the optical microscopy images of Fig. 5C.

\section{Release Studies}

The methodology enables the production of the hydrogel beads at the air-solid interface, which means that, in principle, it is possible to avoid the loss of the drugs dissolved in the polymeric solution. Insulin and BSA were used as models of low and high molecular weight bioactive substances. The release profiles at $37^{\circ} \mathrm{C}$ and room temperature from dextran-MA/PNIPAAm beads are shown in Figs. 7 and 8. The amounts released were quantified using the Micro BCA ${ }^{\mathrm{TM}}$ Protein Assay Kit. Insulin and BSA release profiles showed a relatively rapid release in the first $5 \mathrm{~h}$, followed by a more sustained release during several days. The initially fast release can be attributed to the presence of the proteins on (or close to) the bead's surface and has been previously observed for other hydrogel-based delivery systems $(42,43)$. The concentration gradient is the driving force for protein diffusion, then high BSA or insulin concentration gradient between the hydrogel surface and the release medium during the very early stage of contact leads to a higher initial burst release and fast release rate $(39,44)$. The slow release observed after $8 \mathrm{~h}$ could be attributed to the slower diffusion of the proteins that are entrapped in the bulk of the spheres and have to migrate to the bead surface.

Observing the release of insulin during $48 \mathrm{~h}$, dextranMA/PNIPAAm 1:1 beads showed superimposable profiles at room temperature and at $37^{\circ} \mathrm{C}$ (Fig. 7). A decrease in dextran amount and the corresponding increase of the relative amount of PNIPAAm led to markedly temperaturedependent release rates. The faster release of insulin at room temperature than at $37^{\circ} \mathrm{C}$ from $1: 5$ and $1: 10$ beads is explained by the diffusion of the low molecular weight protein through the pores of the matrix when beads are in swollen state (45). When the beads were immersed in PBS at $37^{\circ} \mathrm{C}$, the surface of the gel shrank immediately and formed a "skin layer" due to the convective forces created by gel deswelling (45). This more impermeable layer slows or prevents the protein diffusion (45).

The release of the high molecular weight protein BSA from dextran-MA/PNIPAAm 1:1 and 1:5 beads at room
Fig. 8 BSA cumulative release from Dextran-MA/PNIPAAm beads at room temperature and at $37^{\circ} \mathrm{C}:(\mathbf{A}) 1: 1$ and $(\mathbf{B}) 1: 5$ beads. Error bars represent the standard deviation. Fluorescent microscope images of I:I Dextran-MA/PNIPAAm beads with albumin-FITC after $(\mathbf{C}) 6 \mathrm{~h},(\mathbf{D}) 10$ days and $(\mathbf{E})$ 20 days of immersion in PBS at $37^{\circ} \mathrm{C}$.
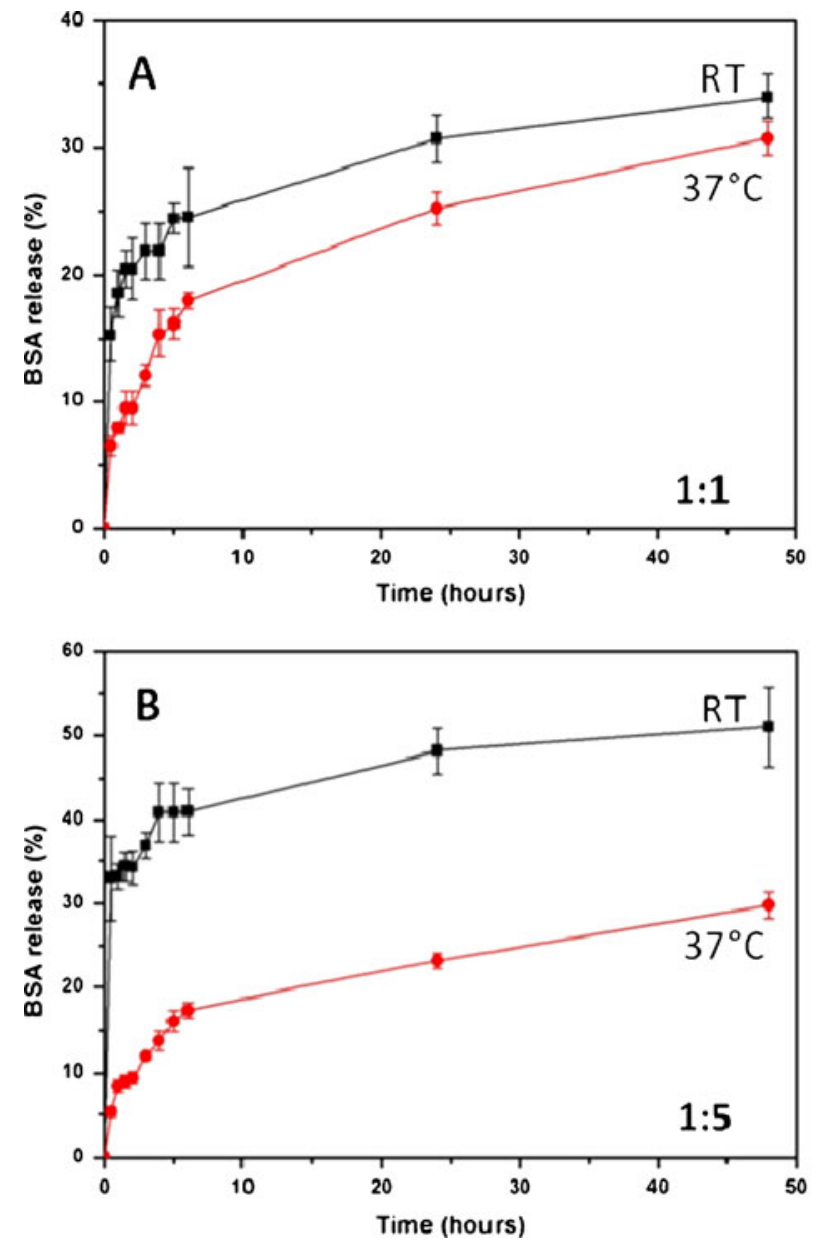
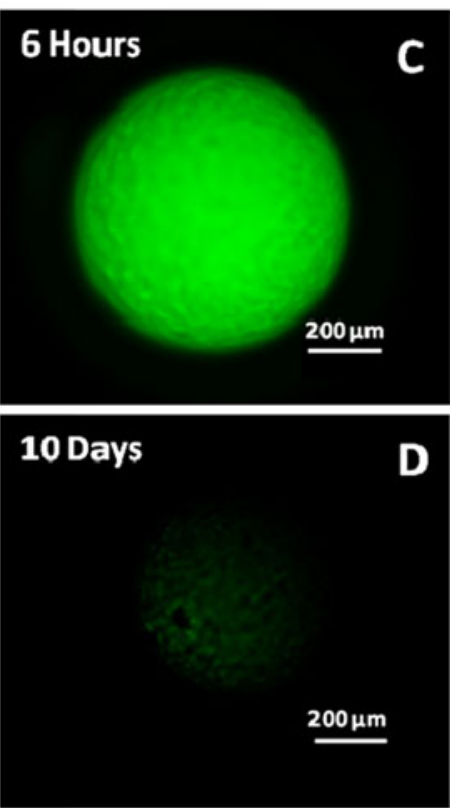

20 Days 
temperature was also faster than at $37^{\circ} \mathrm{C}$ (Fig. $8 \mathrm{~A}$ and B). As explained above, the ability to the beads to swell at room temperature leads to the increase of the pore size in the hydrogel structure that allows the diffusion of the BSA to the medium. The slower release at $37^{\circ} \mathrm{C}$ may be explained by the shrinking behavior of the bead's structure and the "skin" formation. Once again, the difference in release rate as a function of the temperature is more evident as the dextran amount decreases. Similar BSA release results were obtained by Moura et al. with alginate/PNIPAAm IPN (43) and by Wu et al. (45) with PNIPAAm hydrogels.

In order to visualize the diffusion of the drug in the hydrogel beads, albumin-FITC was used to trace the drug model. Fluorescence microscopy allowed the observation of the albumin-FITC distribution in the beads at different times. Figure $8 \mathrm{C}, \mathrm{D}$ and $\mathrm{E}$ show the homogeneous protein distribution on bead's surface. As the time progresses, the intensity of the fluorescence decreases. This shows in a qualitative way the diffusion of the protein to the medium. Very weak fluorescence intensity could be observed on the hydrogel spheres after 20 days, which means that a small quantity of albumin-FITC still remains in the beads.

\section{CONCLUSIONS}

Inspired by the rolling water drop on a lotus leaf, superhydrophobic surfaces were successfully employed to produce smart hydrogel beads suitable as bioactive molecules carrier systems. In particular, the method enabled the development of dextran-MA/PNIPAAm beads crosslinked in an environment without liquid-liquid interactions that allowed fixing the bioactive agent during the hardening step of the particles. The produced beads showed temperature-responsive swelling. The rate of the release of bioactive molecules can be tuned by the bead's composition and the temperature of the medium. Therefore, the beads are potentially useful for controlled delivery of proteins. We envision that such technology may be employed in the biomedical field, namely for pharmaceutical technology and in tissue engineering.

\section{ACKNOWLEDGMENTS}

The authors acknowledge funding from the project: PTDC/QUI/68804/2006 (FCT), IBEROMARE-Procept, FEDER and MICINN (SAF2008-01679). The research leading to these results has also received funding from the European Union Seventh Framework Programme (FP7/ 2007-2013) under grant agreement \#NMP4-SL-2009229292. The authors are grateful to project DISC
REGENERATION, Collaborative Project-Large-scale integrating project, NMP3-LA-2008-213904 for the use of the UV lamp.

\section{REFERENCES}

1. Goldberg M, Langer R, Jia XQ. Nanostructured materials for applications in drug delivery and tissue engineering. J Biomater Sci Polym Ed. 2007;18(3):241-68.

2. Yang LB, Chu JS, Fix JA. Colon-specific drug delivery: new approaches and in vitro/in vivo evaluation. Int J Pharm. 2002;235 $(1-2): 1-15$.

3. Peppas NA, Hilt JZ, Khademhosseini A, Langer R. Hydrogels in biology and medicine: from molecular principles to bionanotechnology. Adv Mater. 2006;18(11):1345-60.

4. Lee KY, Yuk SH. Polymeric protein delivery systems. Prog Polym Sci. 2007;32(7):669-97.

5. Kim S, Kim JH, Jeon O, Kwon IC, Park K. Engineered polymers for advanced drug delivery. Eur J Pharm Biopharm. 2009;71 (3):420-30.

6. Kopecek J. Smart and genetically engineered biomaterials and drug delivery systems. Eur J Pharm Sci. 2003;20(1):1-16.

7. Yeo Y, Baek N, Park K. Microencapsulation methods for delivery of protein drugs. Biotechnol Bioprocess Eng. 2001;6(4):213-30.

8. Gillot $\mathrm{S}$, inventor Chia-based fatty acids food product, rich in omega-3, with good stability. Patent WO/2010/012320. 2010.

9. O'Donnell PB, McGinity JW. Preparation of microspheres by the solvent evaporation technique. Adv Drug Deliv Rev. 1997;28 (1):25-42.

10. Guo Z, Liu W, Su B-L. Superhydrophobic surfaces: From natural to biomimetic to functional. Journal of Colloid and Interface Science. In Press, Corrected Proof.

11. Song W, Lima AC, Mano JF. Bioinspired methodology to fabricate hydrogel spheres for multi-applications using superhydrophobic substrates. Soft Matter. 2010;6(23):5868-71.

12. Sinha VR, Kumria R. Polysaccharides in colon-specific drug delivery. Int J Pharm. 2001;224(1-2):19-38.

13. Ruel-Gariepy E, Leroux JC. In situ-forming hydrogels - review of temperature-sensitive systems. Eur J Pharm Biopharm. 2004;58 (2):409-26.

14. Mano JF, Silva GA, Azevedo HS, Malafaya PB, Sousa RA, Silva $\mathrm{SS}$, et al. Natural origin biodegradable systems in tissue engineering and regenerative medicine: present status and some moving trends. J R Soc Interface. 2007;4(17):999-1030.

15. Kim DJ, Heo JY, Kim KS, Choi IS. Formation of thermoresponsive poly(nisopropylacrylamide)/dextran particles by atom transfer radical polymerization. Macromol Rapid Commun. 2003;24(8):517-21.

16. Kim IS, Jeong YI, Kim DH, Lee KH, Kim SH. Albumin release from biodegradable hydrogels composed of dextran and poly (ethylene glycol) macromer. Arch Pharm Res. 2001;24(1):69-73.

17. Crepon B, Jozefonvicz J, Chytry V, Rihova B, Kopecek J. Enzymatic degradation and immunogenic properties of derivatized dextrans. Biomaterials. 1991;12(6):550-4.

18. Kim SH, Chu CG. Synthesis and characterization of dextranmethacrylate hydrogels and structural study by SEM. J Biomed Mater Res. 2000;49(4):517-27.

19. ZhangJT, Petersen S, Thunga M, Leipold E, Weidisch R, Liu XL, et al. Micro-structured smart hydrogels with enhanced protein loading and release efficiency. Acta Biomater. 2009;6(4):1297-306.

20. Santos JR, Alves NM, Mano JF. New thermo-responsive hydrogels based on poly (N-isopropylacrylamide)/hyaluronic acid semi- 
interpenetrated polymer networks: swelling properties and drug release studies. J Bioact Compat Polym. 2010;25(2):169-84.

21. Shi J, Alves NM, Mano JF. Drug release of $\mathrm{pH} /$ temperatureresponsive calcium alginate/poly(N-isopropylacrylamide) semiIPN beads. Macromol Biosci. 2006;6(5):358-63.

22. Shin BC, Jhon MS, Lee HB, Yuk SH. pH/temperature dependent phase transition of an interpenetrating polymer network: anomalous swelling behavior above lower critical solution temperature. Eur Polym J. 1998;34(11):1675-81.

23. Alvarez-Lorenzo G, Concheiro A, Dubovik AS, Grinberg NV, Burova TV, Grinberg VY. Temperature-sensitive chitosan-poly (N-isopropylacrylamide) interpenetrated networks with enhanced loading capacity and controlled release properties. J Control Release. 2005;102(3):629-41.

24. Erbil HY, Demirel AL, Avci Y, Mert O. Transformation of a simple plastic into a superhydrophobic surface. Science. 2003;299 (5611):1377-80

25. Oliveira NM, Neto AI, Song W, Mano JF. Two-dimensional open microfluidic devices by tuning the wettability on patterned superhydrophobic polymeric surfaces. Appl Phys Express. 2010;3.

26. Song WL, Veiga DD, Custodio CA, Mano JF. Bioinspired degradable substrates with extreme wettability properties. Adv Mater. 2009;21(18):1830.

27. Yao X, Chen QW, Xu L, Li QK, Song YL, Gao XF, et al. Bioinspired ribbed nanoneedles with robust superhydrophobicity. Adv Funct Mater. 2010;20(4):656-62.

28. Qian BT, Shen ZQ. Fabrication of superhydrophobic surfaces by dislocation-selective chemical etching on aluminum, copper, and zinc substrates. Langmuir. 2005;21(20):9007-9.

29. van Dijk-Wolthuis WNE, Franssen O, Talsma H, van Steenbergen MJ, Kettenes-van den Bosch JJ, Hennink WE. Synthesis, characterization, and polymerization of glycidyl methacrylate derivatized dextran. Macromolecules. 1995;28(18):6317-22.

30. Reis AV, Fajardo AR, Schuquel ITA, Guilherme MR, Vidotti GJ, Rubira AF, et al. Reaction of glycidyl methacrylate at the hydroxyl and carboxylic groups of poly(vinyl alcohol) and poly(acrylic acid): is this reaction mechanism still unclear? J Org Chem. 2009;74 (10):3750-7.

31. Yuan ZQ, Ghen H, Tang JX, Chen X, Zhao DJ, Wang ZX. Facile method to fabricate stable superhydrophobic polystyrene surface by adding ethanol. Surf Coat Technol. 2007;201(16-17):7138-42.

32. Zhao N, Xu J, Xie Q, Weng L, Guo X, Zhang X, et al. Fabrication of biomimetic superhydrophobic coating with a micro-nano-binary structure. Macromol Rapid Commun. 2005;26(13):1075-80.
33. de Givenchy EPT, Amigoni S, Martin G, Andrada G, Caillier L, Geribaldi S, et al. Fabrication of superhydrophobic PDMS surfaces by combining acidic treatment and perfluorinated monolayers. Langmuir. 2009;25(11):6448-53.

34. Qiu Y, Park K. Environment-sensitive hydrogels for drug delivery. Adv Drug Deliv Rev. 2001;53(3):321-39.

35. Shi J, Alves NM, Mano JF. Chitosan coated alginate beads containing poly(N-isopropylacrylamide) for dual-stimuliresponsive drug release. J Biomed Mater Res B. 2008;84B (2):595-603.

36. Shi J, Liu LH, Sun XM, Cao SK, Mano JF. Biomineralized polysaccharide beads for dual-stimuli-responsive drug delivery. Macromol Biosci. 2008;8(3):260-7.

37. Santo VE, Frias AM, Carida M, Cancedda R, Gomes ME, Mano $\mathrm{JF}$, et al. Carrageenan-based hydrogels for the controlled delivery of PDGF-BB in bone tissue engineering applications. Biomacromolecules. 2009;10(6):1392-401.

38. Pitarresi G, Palumbo FS, Giammona G, Casadei MA, Moracci FM. Biodegradable hydrogels obtained by photocrosslinking of dextran and polyaspartamide derivatives. Biomaterials. 2003;24 (23):4301-13.

39. Zhang XZ, Wu DQ Chu CC. Synthesis and characterization of partially biodegradable, temperature and $\mathrm{pH}$ sensitive Dex-MA/ PNIPAAm hydrogels. Biomaterials. 2004;25(19):4719-30.

40. Zhang J, Peppas NA. Synthesis and characterization of $\mathrm{pH}-$ and temperature-sensitive poly(methacrylic acid)/poly(N-isopropylacrylamide) interpenetrating polymeric networks. Macromolecules. 1999;33(1):102-7.

41. Kim SH, Chu CC. Pore structure analysis of swollen dextranmethacrylate hydrogels by SEM and mercury intrusion porosimetry. J Biomed Mater Res. 2000;53(3):258-66.

42. Piai JF, de Moura MR, Rubira AF, Muniz EC. Kinetic study of bovine serum albumin (BSA) released from alginate-Ca2+/ PNIPAAm hydrogels. Macromol Symp. 2008;266(1):108-13.

43. de Moura MR, Aouada FA, Favaro SL, Radovanovic E, Rubira AF, Muniz EC. Release of BSA from porous matrices constituted of alginate-Ca2+ and PNIPAAm-interpenetrated networks. Mater Sci Eng C Mater Biol Appl. 2009;29(8):2319-25.

44. Naddaf AA, Tsibranska I, Bart HJ. Kinetics of BSA release from poly(N-isopropylacrylamide) hydrogels. Chem Eng Process. 2010;49(6):581-8.

45. Wu J-Y, Liu S-Q, Heng PW-S, Yang Y-Y. Evaluating proteins release from, and their interactions with, thermosensitive poly $(\mathrm{N}$ isopropylacrylamide) hydrogels. J Control Release. 2005;102 (2):361-72. 